First Peoples Child \& Family Review

A Journal on Innovation and Best Practices in Aboriginal Child Welfare Administration,

Research, Policy \& Practice

\title{
Indigenous knowledge and research: The míkiwáhp as a symbol for reclaiming our knowledge and ways of knowing
}

\section{Michael Hart}

Volume 3, Number 1, 2007

URI: https://id.erudit.org/iderudit/1069528ar

DOI: https://doi.org/10.7202/1069528ar

See table of contents

Publisher(s)

First Nations Child and Family Caring Society of Canada

\section{ISSN}

1708-489X (print)

2293-6610 (digital)

Explore this journal

Cite this article

Hart, M. (2007). Indigenous knowledge and research: The míkiwáhp as a symbol for reclaiming our knowledge and ways of knowing. First Peoples Child \& Family Review, 3(1), 83-90. https://doi.org/10.7202/1069528ar
Article abstract

This paper is based on the unique learning that the author obtained from various Cree and Anishinaabe Elders regarding Indigenous knowledge. The author's experience with learning about Indigenous Knowledge is expressed through a review of the literature conducted on Indigenous knowledge and through symbolic imagery using the míkiwáhp (or "lodge"). Included is a discussion on appropriate considerations to utilizing Indigenous knowledge and its development in the context of colonial oppression over Indigenous peoples.
This document is protected by copyright law. Use of the services of Erudit (including reproduction) is subject to its terms and conditions, which can be viewed online.

https://apropos.erudit.org/en/users/policy-on-use/ 
First Peoples Child \& Family Review

A Journal on Innovation and Best Practices in Aboriginal Child Welfare

Administration, Research, Policy \& Practice

Volume 3, Number 1, 2007, pp. 83-90

\section{Indigenous knowledge and research: The míkiwáhp as a symbol for reclaiming our knowledge and ways of knowing}

Michael Hart

While not readily recognized or respected by Amer-European societies, Indigenous ${ }^{1}$ knowledge exists. Indigenous knowledge has contributed to the well being of not only Indigenous nations, but the world population in general. Yet, little has been done to support its continuing development, particularly in academia. Instead, Indigenous peoples have faced life times of colonial oppression that has impeded, trivialized, and oppressed our knowledge and ways of coming to know. While there have been generations of Indigenous peoples working in ways that counter this oppression, there have been recent writings calling on the need for Indigenous people to take greater control of, and provide direction and support for the continuing development of our ways of coming to know and our knowledge. In an effort to support this call, I have attempted to identify some understandings of what is Indigenous knowledge through a review of literature and the use of a symbolic image, the míkiwáhp (Cree for lodge; also referred to as a teepee). I present the structure of the míkiwáhp as a means to picture the symbols and ideas various Elders have shared with me about our Indigenous knowledge. With this picture in mind and understandings in place, I then discuss the relation of Indigenous

\begin{abstract}
This paper is based on the unique learning that the author obtained from various Cree and Anishinaabe Elders regarding Indigenous knowledge. The author's experience with learning about Indigenous Knowledge is expressed through a review of the literature conducted on Indigenous knowledge and through symbolic imagery using the míkiwáhp (or "lodge"). Included is a discussion on appropriate considerations to utilizing Indigenous knowledge and its development in the context of colonial oppression over Indigenous peoples.
\end{abstract}

knowledge to some research paradigms, particularly the naturalistic paradigm. I follow this discussion with a review of some points that should be considered when addressing Indigenous knowledge and its development in the context of the colonial oppression Indigenous peoples have faced.

\section{Identifying Indigenous Knowledge}

Battiste and Henderson (2000) have suggested that there is no short answer to explaining what is Indigenous knowledge. They identified that it is not an extension of the European based knowledge system, but a distinct knowledge 
system in its own right. While there are connections that exist across and within this system, variations exist between the methods, concepts, experiences, and values used by various Indigenous peoples to gain their knowledge. Thus, there are differences in interpretations and applications of Indigenous knowledge (Battiste \& Henderson, 2000; Cajete, 2000). As such, it is important to note that an umbrella Aboriginal world view does not exist (Simpson, 2000a) and that pan-Indigenous references should only be seen as stepping stones in Indigenous peoples' progress.

With these points in mind, several authors have identified significant aspects to understanding what is Indigenous knowledge. One of the dominating features is its holistic base (Battiste \& Henderson, 2000; Cajete, 2000, 1999). Unlike the positivistic empiricism paradigm that dominants Amer-European knowledge, Indigenous knowledge does not separate realities into disciplines, such as religion, philosophy, art, physical sciences, and social sciences. Instead, these systems are often looked at and addressed together. Understandings stemming from these various sources are seen as being mutually dependent upon one another, thus making it irrational to divide them.

Being holistically based, Indigenous knowledge is dependent upon the relationships within personal and social contexts. On a personal level, Indigenous knowledge relies upon subjective interpretations and experiences. The primary goal is self-knowledge (Cajete, 1999). Giving a more detailed explanation, Henderson (2000) identifies that the goal of Indigenous knowledge is to understand and attempt to contain the energies that infuse everything in order to create a lifestyle that is harmonious with the local ecosystem. Knowledge is developed on a personal level through subjective reflection and participating in ceremonial and stage based processes (Cajete, 1999; Ermine, 1995). Thus, it is gained through experience and all the senses and instincts (Henderson, 2000). On a social level, Indigenous knowledge is highly localized in that knowledge is based upon the environment and situations encountered by learners (Cajete, 2000, 1999). It has a focus on "the web of relationships between humans, animals, plants, natural forces, spirits, and land forms in particular localities, as opposed to discovering particular "laws"' (Battiste \& Henderson, 2000, p. 44).

Indeed, Indigenous knowledge is dependent upon people's experiences with their local ecosystems (Henderson, 2000). Battiste and Henderson (2000) have even suggested that the changing ecosystem is the ultimate source of knowledge and that the common expression of Indigenous knowledge lies in the vibrant relationship between the people, their ecosystem, and the other living beings and spirits that share the land. Indigenous knowledge is developed through people's attempts to understand their relationship with local ecosystems, thus Indigenous ways of coming to know are orientated to a space and place (Cajete, 2000). As such, the ecosystem itself is another key aspect of the holistic base of Indigenous knowledge.

This holistic base also includes the physical and spiritual realms since there is no division between science and spirituality. Indeed, every act and every being is seen as sacred (Peat, 1994). There is a recognition of Indigenous ways of learning through the physical world which includes such methodologies and practices as observation, experiential learning, and apprenticeship (Cajete, 1999, 2000). 
Importantly, these physical world practices are augmented by ways of learning and knowledge development that are based upon spiritual practices. As stated by Ermine (1995), "the culture of the Aboriginal recognized and affirmed the spiritual through practical application of inner-space discoveries" ( $p$. $110)$, or what Peat (1994) referred to as "experimentation of the mind" (p. 251). These applications include fasting, reflecting upon dreams, and ceremonies (Cajete, 1999, 2000; Peat, 1994). The knowledge gained through these applications is used to guide one's life in both the spiritual and physical world.

Significant to this guiding process are Elders. Elders have taken the time to learn the practices and ceremonies of their Indigenous ancestors and are seen by their community as holders of knowledge (Cajete, 1999; Peat, 1994; Simpson, 2000a; Stiegelbauer, 1996). Through apprenticeship like training, Elders guide the transmission of Indigenous knowledge from previous generations to future generations. With their guidance and support, they facilitate learning through ceremonies, stories, and role modelling (Cajete, 2000; Couture, 1996; Stiegelbauer, 1996). Thus, as the present reflection of generations of Indigenous knowledge they are key links in the multigenerational aspects of Indigenous knowledge.

From this brief review of literature on Indigenous knowledge, it can be said that such knowledge is holistic, personal (subjective), social (dependent upon inter-relations), and highly dependent upon local ecosystems. It is also inter-generational, incorporates the spiritual and physical, and heavily reliant on Elders to guide its development and transmission. While these descriptive features are unlikely to completely encompass what is Indigenous knowledge-indeed several authors have identified some additional points (Cajete, 2000; Henderson, 2000; Simpson, 2000a) - these features are evident in stories presented and processes followed by Cree and Anishinaabe Elders in Central Canada. The following reflections serve to symbolically illustrate some of these features of Indigenous knowledge.

\section{Picturing Indigenous Knowledge}

As I attempted to find my way in the EuroCanadian based helping and educational systems, I have sought out the support and direction of Elders knowledgeable in our ways of learning and helping ${ }^{2}$. In part of this search, I have listened to them discuss the míkiwáhp (Cree-meaning lodge; also known as a teepee) metaphorically in relation to knowledge and meaning. They described how the lodge was erected. Three, sometimes four poles were initially tied together with a rope. The narrow ends of the poles were raised into the air while the other ends were firmly placed upon the earth. Each pole's base was placed so that it stood apart from the others, while the opposite end was placed so that it leaned against the other poles. One by one, additional poles were placed to lean upon the initial poles and tied in by having the rope wrapped around the added pole. Soon, there was a circle of poles leaning and dependent upon one another. All were connected by the rope. A final pole, of which was tied the lodge's cover, was place to lean upon the already standing poles. The cover was pulled around all of the poles to encompass the circle. The ends of the cover were joined together with wooden pegs, like the seam of a skirt. Openings remained at the top of the lodge which acted as a venting system, and the cut out at the bottom which acted as its entrance. 
The Elders also spoke of the different aspects of the lodge. One focussed upon the fire in the middle of the lodge and how it maintained the warmth. Another talked about how a person standing on the outside could see parts of the poles that extended from the inside through the top opening to the outside, and how the part that could be seen was on one side of the lodge while the part which could not been seen was on the opposite side. Another commented on how you can only see the outline of each pole from the outside since the covering shielded the details within the lodge. The openings of the lodge were also discussed. The opening on top of the lodge allowed for the sky to be seen, while the opening near the ground acted as the doorway for others to enter the lodge.

In listening further to these Elders, I came to see that each pole represented the understanding and perspective of a person. These understandings stand strongest when they are firmly grounded on the earth, thus reflecting the importance of locality and dependence upon the ecosystem. As with much understandings, there are core elements which are central to the development of the collective knowledge. This is represented by the first poles that are tied together. Each additional pole is the understanding contributed by each additional person. The unification of contributions is developed and reflected by the rope that encompasses all of the poles. The collective understanding is as strong as the tied rope and dependent upon how well each contributing understanding is grounded on the earth. Recalling that each pole is on one side of the lodge at the base and on the other side as it extends past the rope to reach outside the upper opening of the lodge, it can be seen that a person not only contributes to the collective knowledge, but develops a new perspective and understanding. While this new understanding becomes visible to others, the base of the understanding is not always understood since it is not seen.

Since the lodge is covered, it is difficult to see from outside the lodge any details other than the impressions of the poles pressing against the covering, the top of the poles reaching outside the lodge, and part of the rope which ties the poles together. Similarly, people who are not part of the collective are unable to get a full appreciation of the details presented in the development of the collective knowledge. They can form impressions of the views held and, like the visible rope and pole tops, they can get a partial understanding of the emerging collective knowledge and individual views. One of the ways to develop a better view of the entire lodge is to enter it, thus, the lower opening of the lodge acts to welcome people into the lodge to get this view. Similarly, outsiders can develop a fuller understanding of the collective and individual understanding by entering and joining with the people. Upon entering the lodge, a person can get an immediate sense of how the fire acts to maintain the warmth of the lodge. This fire represents the spirit of the collective. Like fire, the spirit has to be nurtured and, in turn, this nurturing helps maintain the collective understanding. Intimately connected to the fire is the opening at the top of the lodge, which reflects our spiritual reach to the Creator. Without the opening, the smoke of the fire could cause the lodge to be uninhabitable, reflecting the need of the proper spiritual direction and guidance.

From the symbolism and understandings presented by the Elders, I have come to recognize that our ways of coming to know have identifiable and distinct features. These features are reflected in many activities stemming from 
Indigenous cultures. For example, the sharing circle directly reflects these features. Sharing circles have many purposes, amongst them being learning and teaching (Hart, 1996, 2002). Sharing circles provide the context for the presentation of each participants' thoughts and the development of a shared understanding. This example emphasizes the importance of these features to Indigenous cultures. Thus, these features need to be considered when continuing the processes of developing Indigenous knowledge, whether these processes are within academic institutions or elsewhere. Within academic institutions, Indigenous knowledge should be considered in regards to research generally, and research with Indigenous peoples specifically.

\section{Relating Indigenous Knowledge to Research}

Weshues, Cadell, Karabanow, Maxwell, and Sanchez (1999) have presented basics beliefs associated with social work research paradigms. The paradigms included were positivist, naturalist, transformational, and heuristic. While it can be demonstrated that the aspects of Indigenous knowledge can be linked readily to naturalistic, transformational, and heuristic paradigms, the aspects identified here demonstrates closer links to the naturalist paradigm. This paradigm sees constructed, multiple, and holistic realities. It sees researcher and the participants interactively involved in mutual learning and sharing responsibility for the research. Findings are bound by time and context, and rest upon the individual reader's assessment. As such, credible or valid research is dependent upon the context of the changing social interactions. It sees inquiry as value-bound and the purpose of research as understanding and descriptive. The process of doing research is emergent, thus follows an inductive process leading to qualitative types of data. Finally, it views the nature of people as social beings who create meaning and make sense of their world.

Clearly, the aspects of Indigenous knowledge presented here reflect these points. However, Indigenous knowledge branches further than these points as evident in the following considerations. Its holistic perspective is much larger in that it is intimately linked to matters of spirit. Spiritual ceremonies are seen as significant, if not vital, pathways to gaining, demonstrating, sharing, and/or respecting knowledge. It makes direct and dependent links between knowledge and the earth. It follows, reflects, and relies upon cycles and patterns found throughout the ecosystem and as such incorporates the earth as a primary part of the context. It is multi-generational. While Indigenous knowledge recognizes the fluidity of social actions and developing meanings, it holds strongly onto traditions and set methodologies (such as particular ceremonies), and relies on Elders to pass on the ever developing knowledge from previous generations.

\section{Appropriate Considerations}

In light of these comparative points, attempts to consider Indigenous knowledge as a reflection of already established paradigms do not serve it respect or justice. Indeed, concerns have been raised of the manner which Indigenous knowledge has been addressed by European based knowledge systems and representatives of such systems. Battiste and Henderson (2000) have noted that the Eurocentric based research community espouses universal principles, thus devaluing diversity. This lack of value of alternative perspective serves those with the power to place their "universal" perspective as front and centre. As Smith (1999) suggested, "the globalization of knowledge and Western 
culture constantly reaffirms the West's view of itself as the centre of legitimate knowledge, the arbitrator of what counts as knowledge and the source of 'civilized' knowledge" (p. 53). In turn, Indigenous knowledge is relegated to outposts of obscure and/or relatively unknown journals and classes. When it is incorporated into the mainstream and acts as a contributing factor in the development of our societies, there is little, if any, recognition that the contribution stems from Indigenous knowledge (Simpson, 2000b). When it is recognized, it is often taken as a commodity to be bought and disenfranchised from Indigenous people (Battiste \& Henderson, 2000; Smith, 2000). This commodification is supported by the compartmentalization based within the positivistic approach. Indeed, this compartmentalization or fragmentation not only supports the commodification of Indigenous knowledge (Smith, 1999), but impedes Indigenous peoples progress towards, and capacity for, holism (Ermine, 1995) and is used to continue the "colonization of the mind" (Battiste \& Henderson, 2000; Smith, 2000).

In light of these concerns, there has been calls for Indigenous people to be preemptive and proactive (Smith, 2000). This includes identifying Indigenous peoples' needs in regards to knowledge development and research (Gilchrist, 1997). While Simpson (2000b) suggests it may be premature to be calling for the development of Indigenous paradigms due to the primary need of addressing the continued colonial oppression that exists, Gilchrist (1997) suggests Indigenous peoples need to follow Indigenous research paradigms for the development of Indigenous knowledge. Similarly, others have called for the following of not only Indigenous paradigms, but also Indigenous research practices (Cajete, 1999; Ermine, 1994). Such paradigms and practices should be viewed on their own basis (Henderson, 2000). In turn, Indigenous people, indeed all people, will have to consider Indigenous knowledge on its own merits. Ultimately, this will require Indigenous people to gain control over information related to their knowledge, heritage, and themselves (Battiste \& Henderson, 2000b). To support these points, Indigenous academics must use their privileged formal education to support Indigenous ways of knowing, methods of knowledge development, research, and social structures (Simpson, 2000a). Otherwise, such academics will only continue to undermine Aboriginal collective intellect and culture.

While these actions are being implemented, if not before, Indigenous peoples will need to address the colonial processes which continue to impede, trivialize, and/or oppress Indigenous knowledge. As Henderson (2000) has stated, "Aboriginal people are daily asked to acquiesce to Eurocentric theories of legal context that are based firmly on fictitious state-of-nature theories and cultural differences. In one way or another, they are asked to validate the colonialists' libel" (p. 248).

This address of colonial process should not be limited to Indigenous peoples. Ideally, all peoples would participate in such an address. In addition, it has been suggested that Eurocentric based scientists need to recognize that their ways are not the only ways to generate knowledge (Simpson, 2000b). Indigenous ways and contributions need to be recognized and affirmed. Indeed, is it not significant that Indigenous nations have contributed to the worlds food staples, pharmaceuticals aids, arts, and goods, as well as produced knowledge in such areas as astronomy, engineering, agriculture, anatomy, botany, and mathematics? Or, are these contributions irrelevant because 
they are not based upon the European and EuroAmerican system of science?

Some authors have recognized Indigenous knowledge and contributions, and call for a broader definition of what constitutes knowledge (Moore, 1998; McDonald and Brownlee, 1995). Linking the call for this recognition to academia, Moore (1998) identified the need to de-emphasize academia's focus on competition of ideas, and replace it with tolerance of the spectrum of human ideas and respect for the holders of these ideas. Thus, the changes that are required to facilitate the growth of Indigenous knowledge are not focussed upon Indigenous peoples. All people are required to make a shift to become more open and sensitive to Indigenous ways of knowing. Peat (1994) has suggested such openness and sensitivity to other than western ideas could be of considerable value to the West in such areas as medicine, biology, farming technology, and physics. For Indigenous people, he suggests that openness and sensitivity could lead to the acknowledgement of the cultural achievements and support Indigenous cultural revival. In other words, such a shift can benefit many peoples, if only we can overcome the fear of differing ways of knowing and the resultant knowledge.

\section{Closing Remarks}

Indigenous knowledge exists. It holds identifiable characteristics and processes, and is derived from Indigenous ways of coming to know. While these characteristics, processes, and ways hold similarities to some European and Euro-American paradigms which guide research, particularly the naturalist paradigm, they are also distinct. As such, there is need for recognition, development, and support of Indigenous knowledge and ways of coming to know. Indeed, Henderson (2000) links the need for Indigenous control, direction, and action over Indigenous knowledge with our continued existence as Indigenous peoples:

As Aboriginal people, we must reclaim our worldviews, knowledge, languages, and order to find the path ahead. We must sustain our relationship with our environment and follow our Elders' advice. We must rebuild our nations on our worldviews and our good values. We must be patient and thorough, because there are no shortcuts in rebuilding ourselves, our families, our relationships, our spiritual ceremonies, and our solidarity. We must use our abilities to make good choices (p.274).

It is my hope that this paper is a step, at least a small one, towards meeting this need.

\section{Endnotes}

1. Indigenous refers to peoples who are the original inhabitants of a land since time immemorial. For this article, the particular Indigenous people included are those who no longer control their own territories due to the usurpation of their lands by colonizing people and/or their decedents.

2. The Elders that I spoke with were of Cree and Anishinaabe ancestry. The symbolism and ideas they shared occurred over several visits. I did not visit all the Elders together, but most often individually. Thus, the ideas presented here are an amalgamation of these visits and their ideas. With that said, I understand that my sharing of these words has become my responsibility and reflect the understanding I have adopted from them.

\section{Bio}

Michael Anthony Hart, a citizen of Fisher River Cree Nation, currently resides in Winnipeg, Manitoba. As a parent of two young boys, he is concerned about the future of his children and the children of Indigenous peoples, and is committed to supporting the ways and views of Indigenous peoples generally, 
and to Cree peoples specifically. To fulfill his commitment, he has worked in the areas of child and family services, addictions, and mental health. More importantly, he continues to spend much time with Indigenous Elders learning about Indigenous ways of helping and supporting. He is presently completing his Ph.D. in social work at the University of Manitoba while working there as a Lecturer.

\section{References}

Battiste, M., \& Henderson, J. S. Y. (2000). Protecting Indigenous knowledge and heritage: A global challenge. Saskatoon: Purich Publishing.

Cajete, G. (1999). Igniting the sparkle: An Indigenous science education model. Skyand, NC: Kivaki Press.

Cajete, G (2000). Native science: Natural law of interdependence. Santa Fe, NM: Clear Light Publishers.

Couture, J. E. (1996). The role of Native Elders: Emergent issues. In D. A. Long \& O. P. Dickason (Eds.), Visions of the heart: Canadian Aboriginal issues (pp. 41-56).Toronto: Harcourt Brace.

Ermine, W. (1995). Aboriginal epistemology. In M. Battiste \& J. Barman (Eds.) First Nations education in Canada: The circle unfolds (pp. 101-112). Vancouver: UBC Press.

Gilchrist, L. (1997). Aboriginal communities and social science research: Voyeurism in transition. Native Social Work Journal 1(1), 69-88.

Hart, M. A. (1996). Sharing circles: Utilizing traditional practice methods for teaching, helping and supporting. In S. O'Meara, \& D. A. West (Eds.), From our eyes: Learning from Indigenous peoples (pp. 59-72). Toronto: Garmond Press.

Hart, M. A. (2002). Seeking mino-pimatisiwin. An Aboriginal approach to helping. Halifax: Fernwood Publishing.

Henderson, J. S. Y. (2000). Ayukpachi: Empowering Aboriginal thought. In M. Battiste (Ed.) Indigenous voice and vision (pp. 248-278). Vancouver: UBC Press.
McDonald, M. \& Brownlee, K. (1995). Research with First Nations peoples. In R. Delaney and Keith Brownlee (Eds.) Northern social work practice (pp. 182-195). Thunder Bay: Lakehead University, Centre for Northern Studies.

Moore, J. H. (1998). Truth and Tolerance in Native American Epistemology. In R. Thorton (Ed.) Studying Native America: Problems and perspectives (pp. 271-305). Madison: University of Wisconsin Press.

Peat, F. D. (1994). Indigenous science. Lighting the seventh fire: The spiritual ways, healing, and science of the Native American (pp. 239-274). Toronto: Canadian Manda Group.

Simpson, L. (2000a). Anishinaabe Ways of Knowing. Aboriginal health, identity, and resources (165185). Winnipeg: Departments of Native Studies and Zoology, and the Faculty of Graduate Studies, University of Manitoba.

Simpson, L. (2000b). Indigenous knowledge and Western Science: Towards new relationships for change. Aboriginal health, identity, and resources (pp. 186-195). Winnipeg: Departments of Native Studies and Zoology, and Faculty of Graduate Studies, University of Manitoba.

Smith, G. H. (2000). Protecting and respecting Indigenous knowledge. In M. Battiste (Ed.) Reclaiming Indigenous voice and vision (pp. 209224). Vancouver: UBC Press.

Smith, L. T. (1999). Colonizing knowledges. Decolonizing methodologies: Research and Indigenous peoples (pp. 58-77). New York: Zed Books.

Stiegelbauer, S. M. (1996). What is an Elder? What do Elders do? First Nations Elders as teachers in culture-based urban organizations. The Canadian Journal of Native Studies, XVI(1), 37-66.

Westhues, A., Cadell, S., Karabanow, J., Maxwell, L., \& Sanchez, M. (1999). The creation of knowledge: Linking research paradigms to practice. Canadian Social Work Review, 16(2), 129-154. 